\title{
Fabrication of Catalytic Membranes for the Treatment of Drinking Water Using Combined Ozonation and Ultrafiltration
}

\author{
BHAVANA S. KARNIK ${ }^{1}$, SIMON H. DAVIES ${ }^{1,3}$, \\ MELISSA J. BAUMANN ${ }^{2}$ AND SUSAN J. MASTEN ${ }^{1 *}$ \\ ${ }^{1}$ Department of Civil \& Environmental Engineering, ${ }^{2}$ Department of Chemical Engineering \& \\ Materials Science, ${ }^{3}$ Department of Biosystems \& Agricultural Engineering \\ Michigan State University, East Lansing, MI 48824, USA \\ * Author to whom all correspondence should be addressed. \\ Fax-(517)355-0250.Email address : masten@egr.msu.edu \\ Submitted to Environmental Science and Technology
}

The Supporting Information section consists of eight pages, including 11 figures showing water quality data for permeate 1 showing effect on number of coatings on the permeate of $15 \mathrm{kD}$ and $5 \mathrm{kD}$ molecular weight cut off membranes, the effect of sintering at two different temperatures on the permeate water quality. Also the TEM images of the iron oxide catalyst particles are shown followed by image showing ceramic membrane coated with iron oxide. The SI includes one table showing typical characteristics of the Lake Lansing water.

Should you have any questions, please contact the corresponding author at masten@egr.msu.edu 


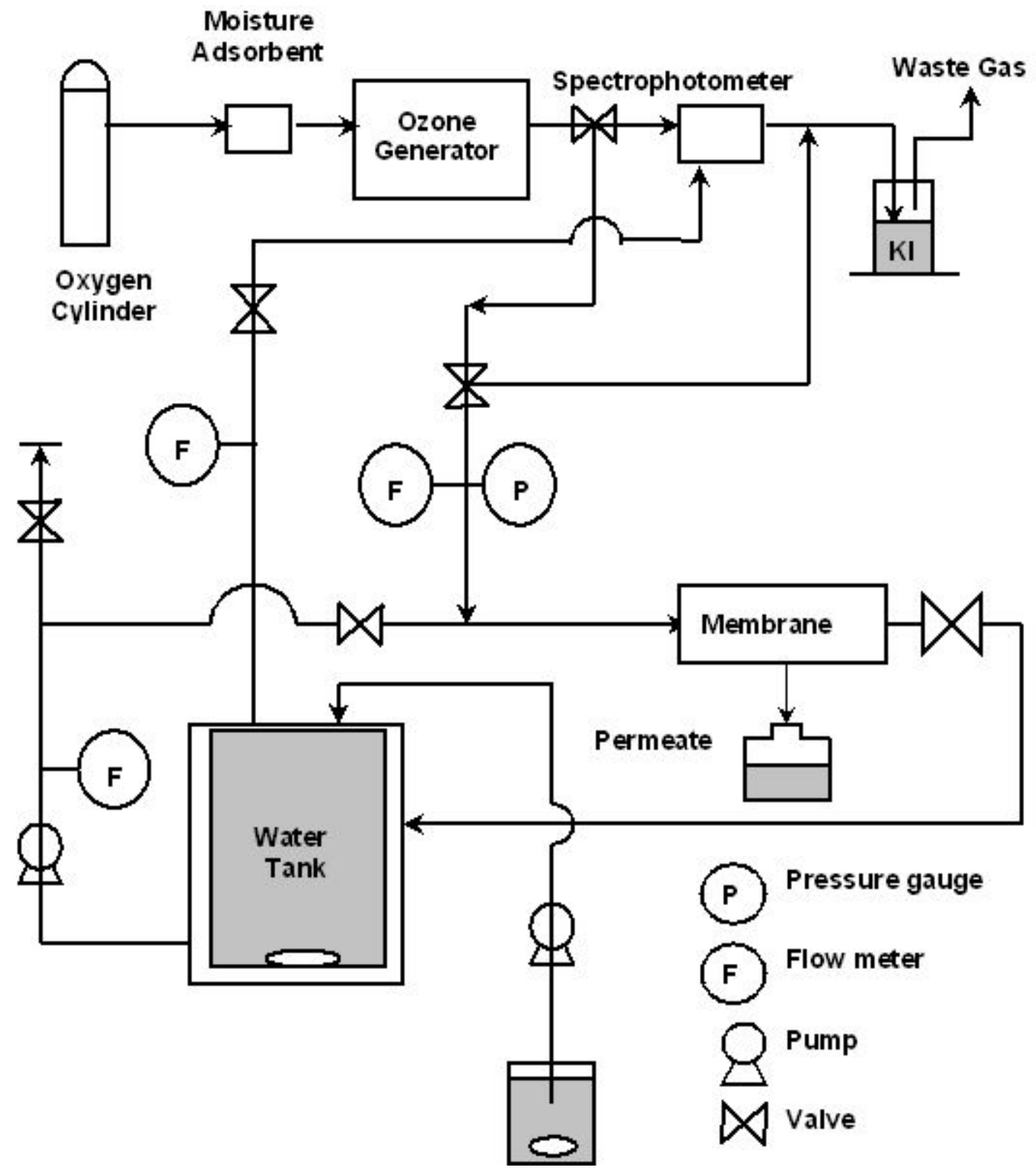

Fig.S1 Schematic Representation of the Ozone-Membrane Filtration System 


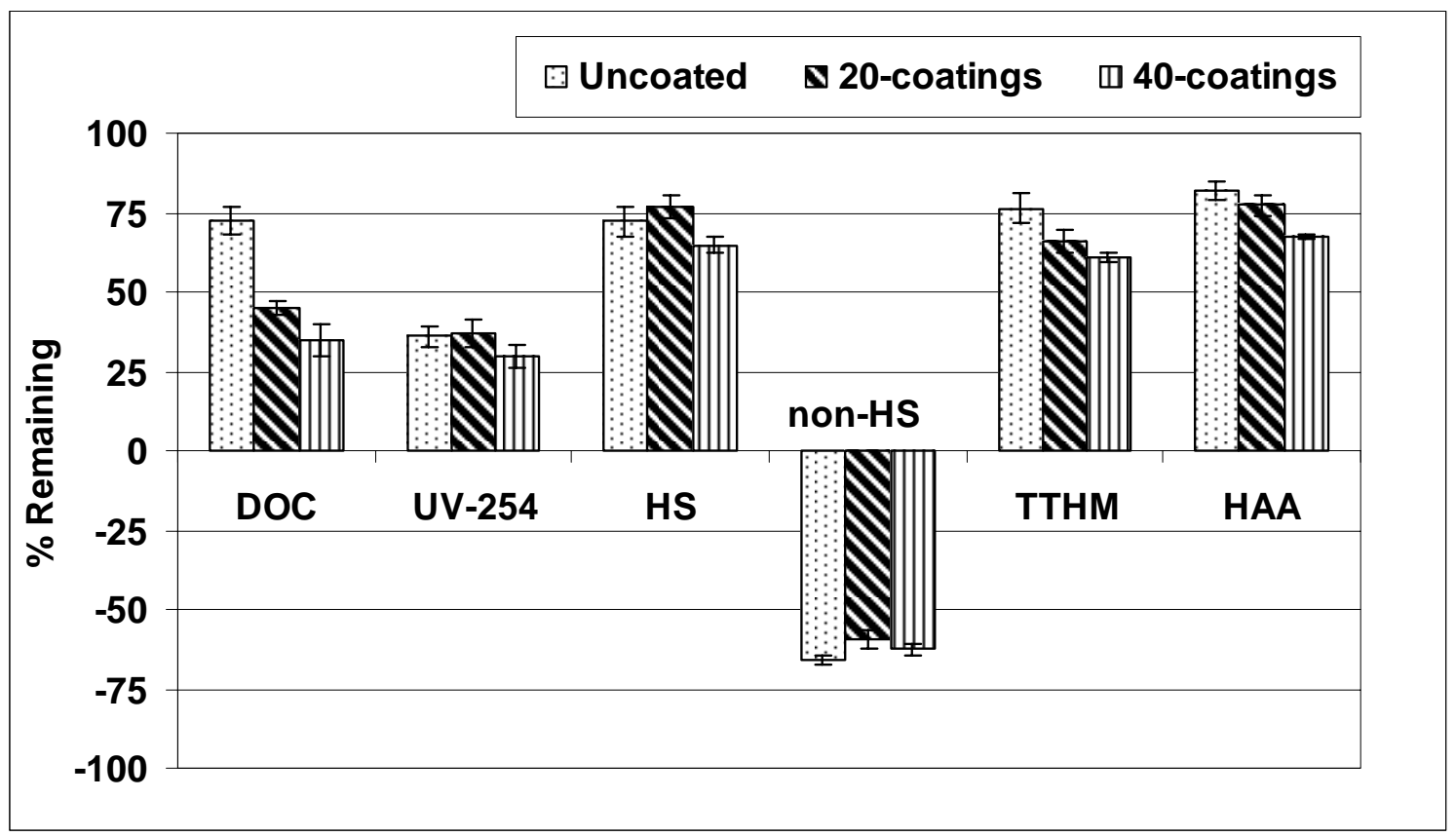

Fig.S2 Effect of the number of catalyst coatings on the water quality of $\mathbf{P 1}$ Experimental setup: Fig. S1 Operating Conditions: Table 1. Membrane Size: 15 kD, 20 or 40 layers, oven baked at $500^{\circ} \mathrm{C} .{ }^{*}$ All values are averages of triplicates within experiments.

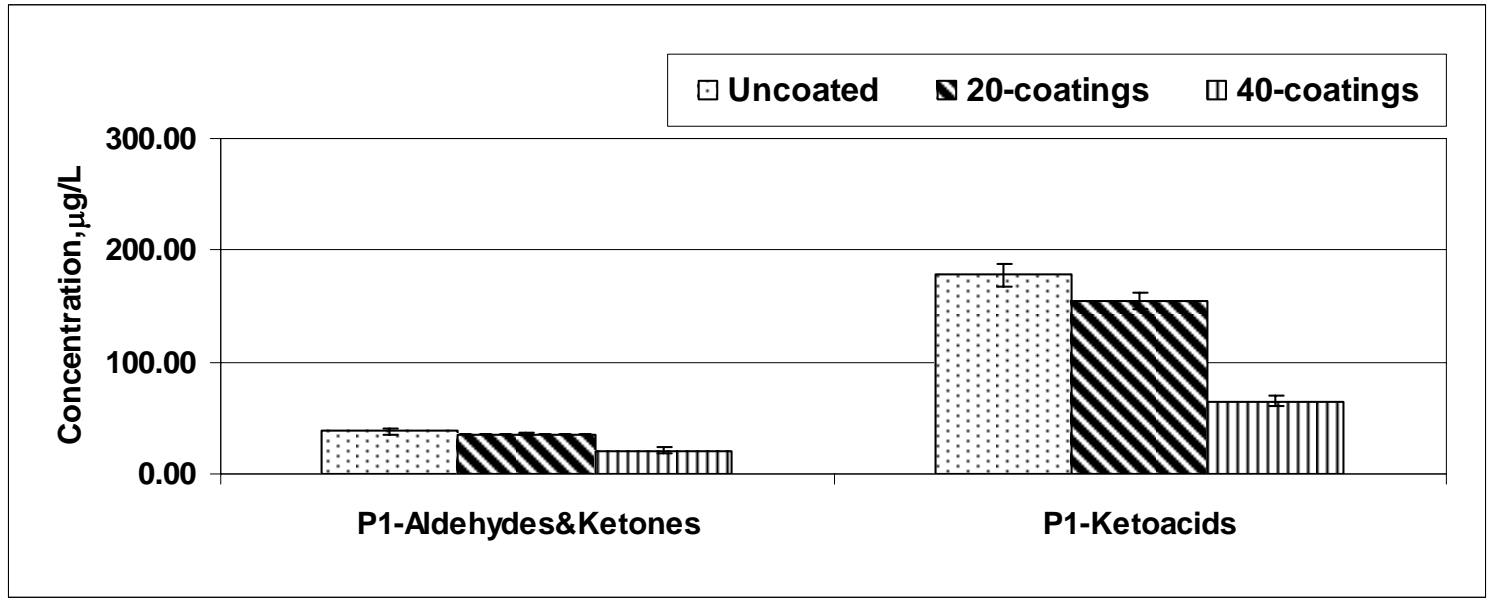

Fig.S3 Effect of the number of catalyst coatings on the concentrations of ozonation by-products in the permeate $P 1$

Experimental setup: Fig. S1 Operating Conditions: Table 1. Membrane Size: 15 kD, 20 or 40 layers, oven baked at $500^{\circ} \mathrm{C} .{ }^{*}$ All values are average of triplicates within experiments. 


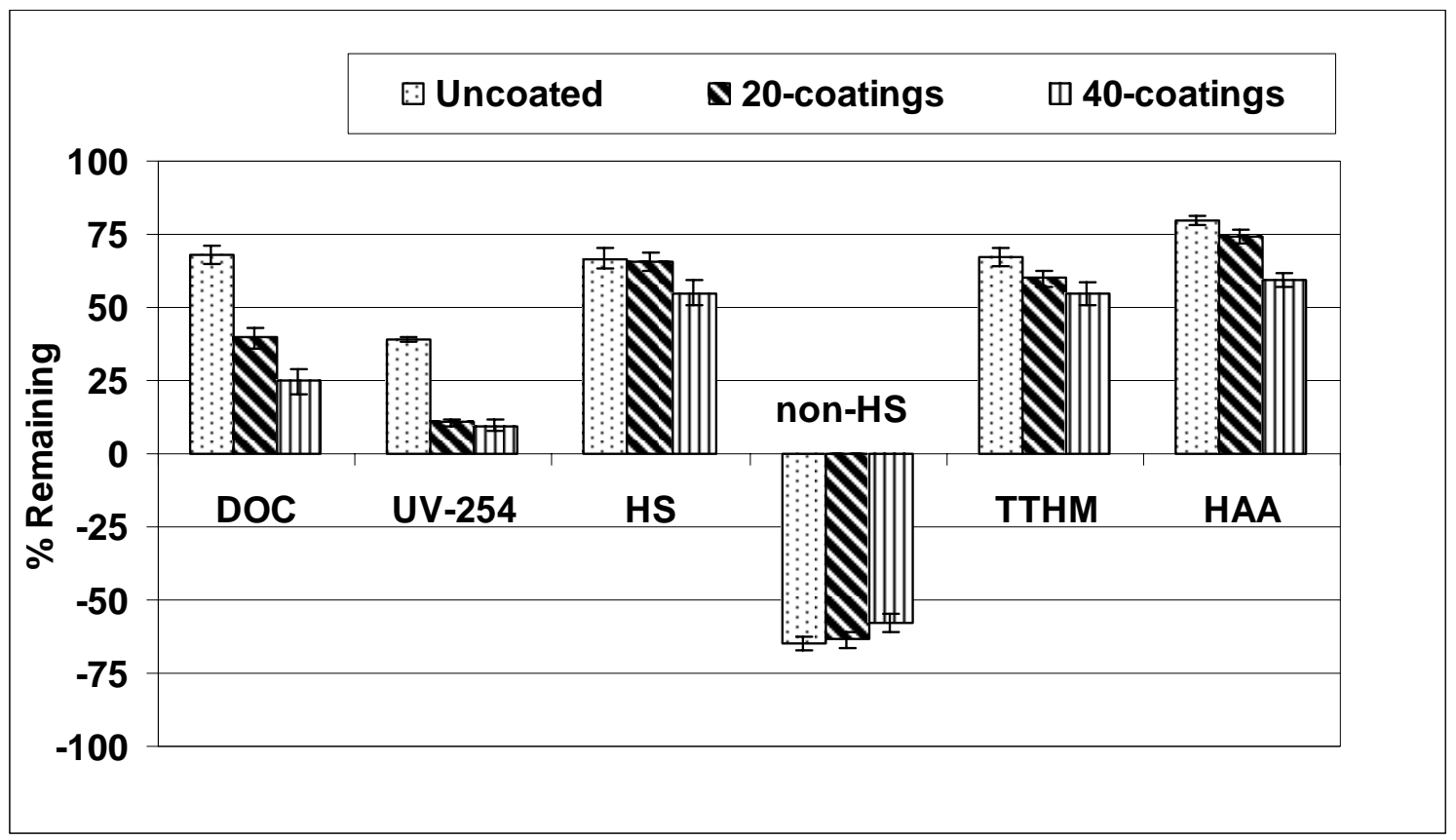

Fig.S4 Effect of the number of catalyst coatings on the water quality of $\mathbf{P 1}$ Experimental setup: Fig. S1 Operating Conditions: Table 1. Membrane Size: 5 kD, 20 or 40 layers, oven baked at $500^{\circ} \mathrm{C} .{ }^{*}$ All values are averages of triplicates within experiments.

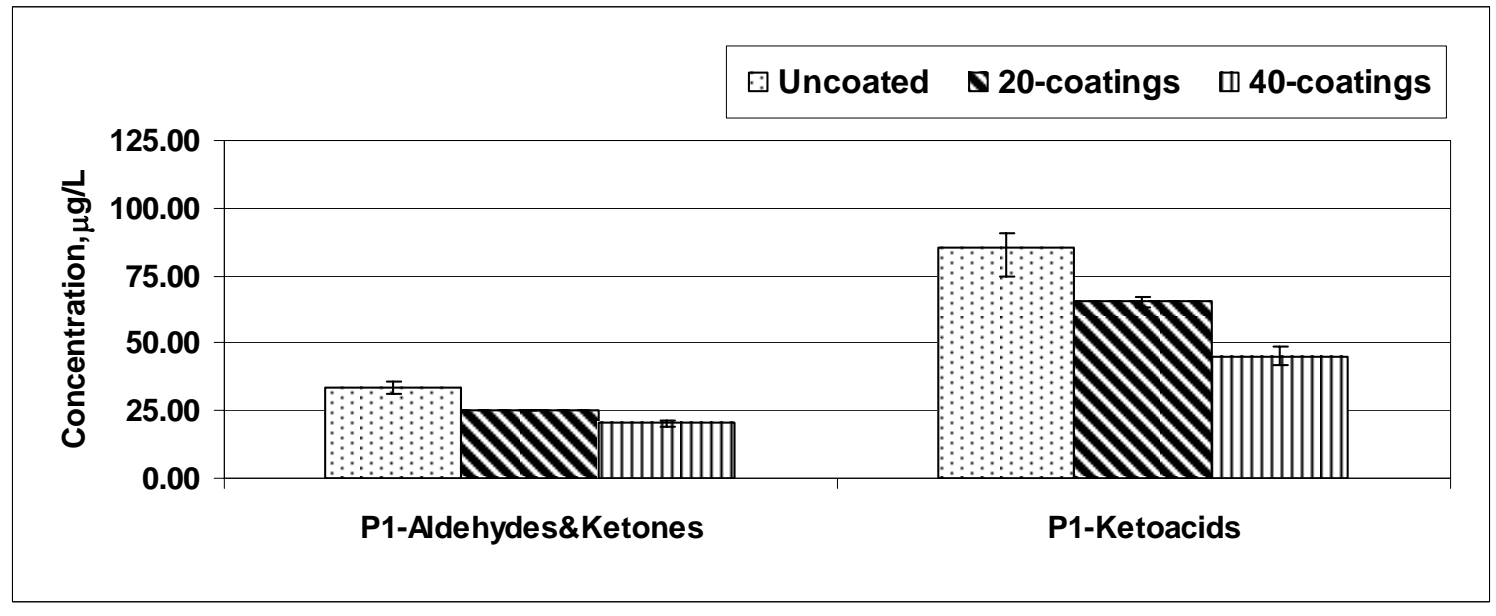

Fig.S5 Effect of the number of catalyst coatings on the concentrations of ozonation by-products in the permeate $P 1$

Experimental setup: Fig. S1 Operating Conditions: Table 1. Membrane Size: 5 kD, 20 and 40 layers, oven baked at $500^{\circ} \mathrm{C} .{ }^{*}$ All values are average of triplicates within experiments. 


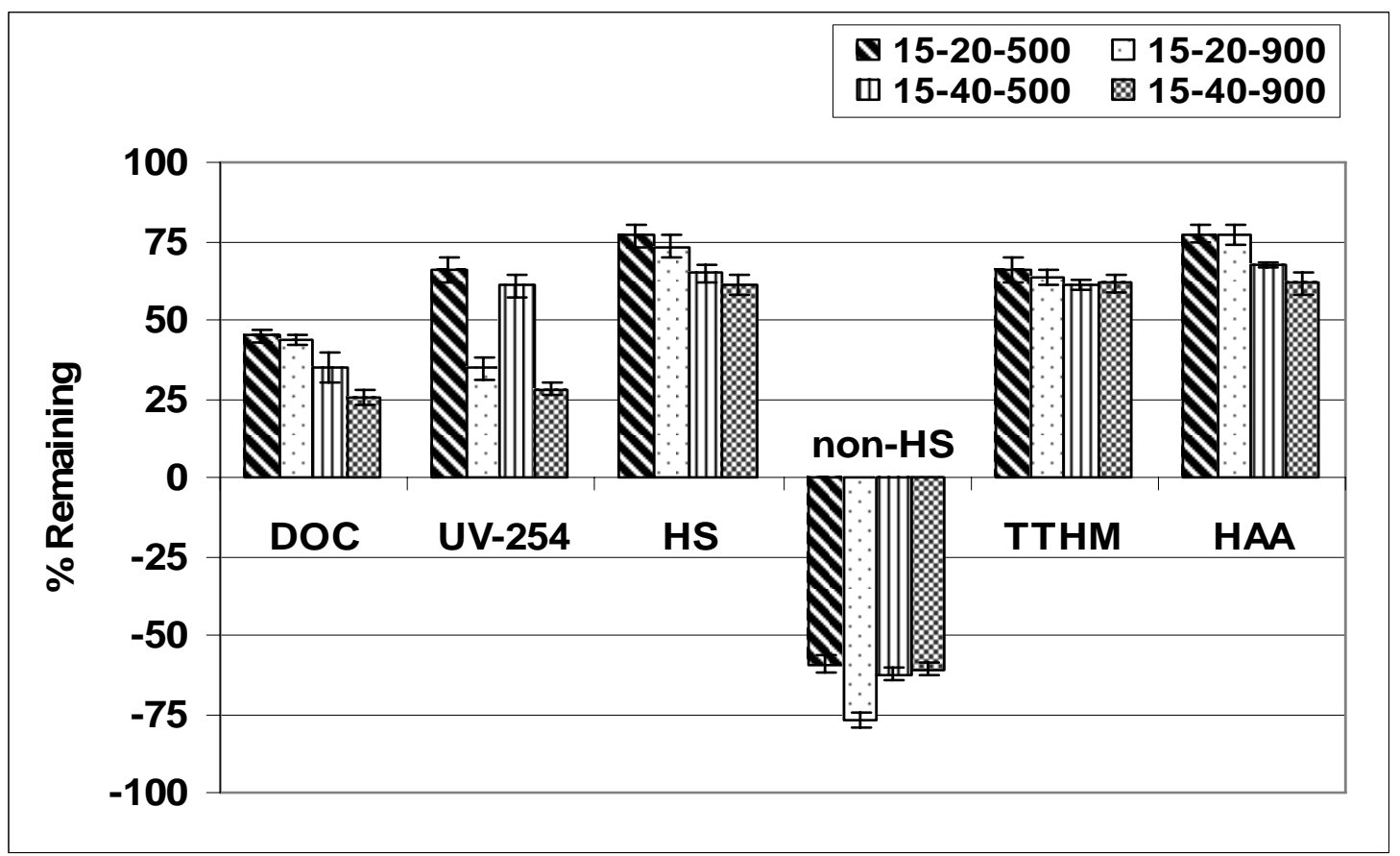

Fig.S6 Water quality for $\mathbf{P 1}$ for two different sintering temperatures Experimental setup: Fig. S1 Operating Conditions: Table 1. Membrane Size: 15 kD, 20 or 40 coatings, oven-baked at $500^{\circ} \mathrm{C}$ or sintered at $900^{\circ} \mathrm{C}$. * All values are average of triplicates within experiments. Explanation of the legend is described in the caption of Fig.1

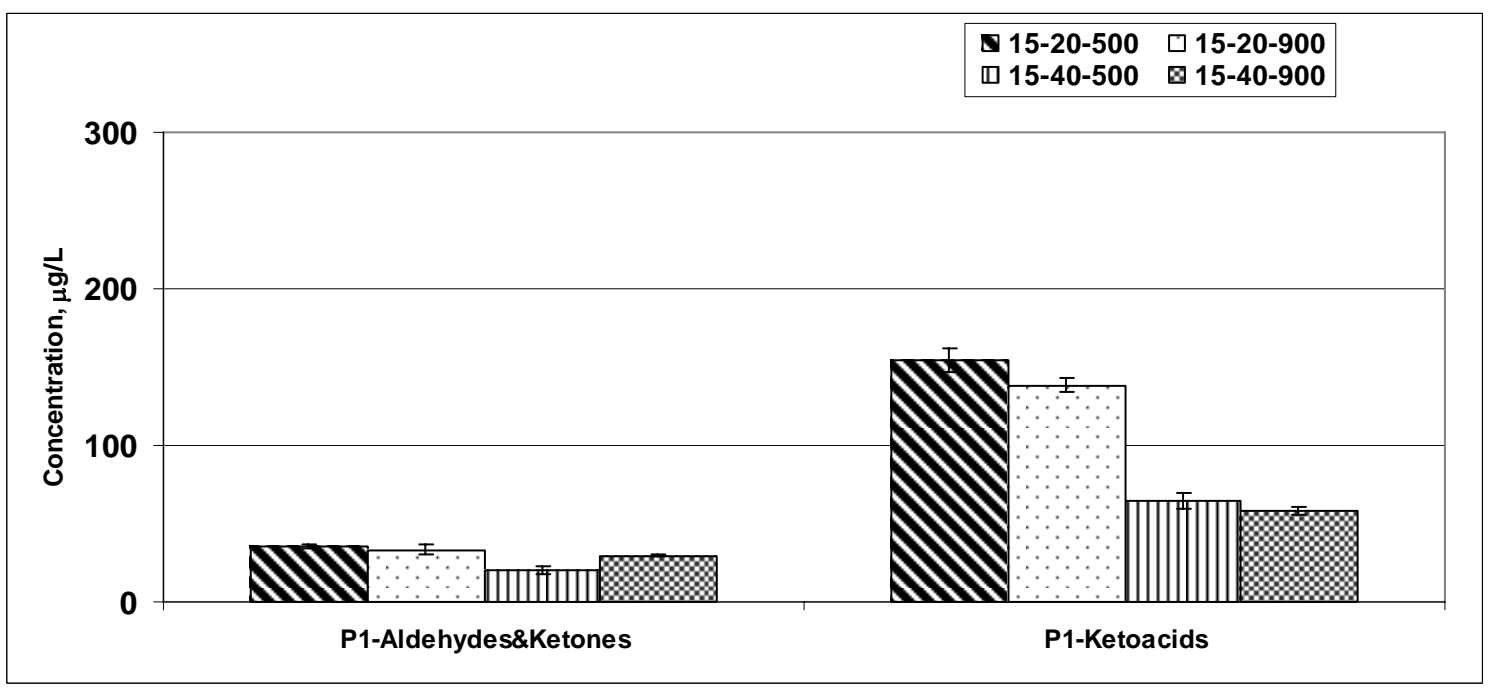

Fig.S7 Concentrations of ozonation by-products in P1 for two different sintering temperatures

Experimental setup: Fig. 1 Operating Conditions: Table 2. Membrane Size: 15 kD, 20 or 40 coatings, oven-baked at $500^{\circ} \mathrm{C}$ or sintered at $900^{\circ} \mathrm{C}$. ${ }^{*}$ All values are average of triplicates within experiments. Explanation of the legend is described in the caption of Fig.1 


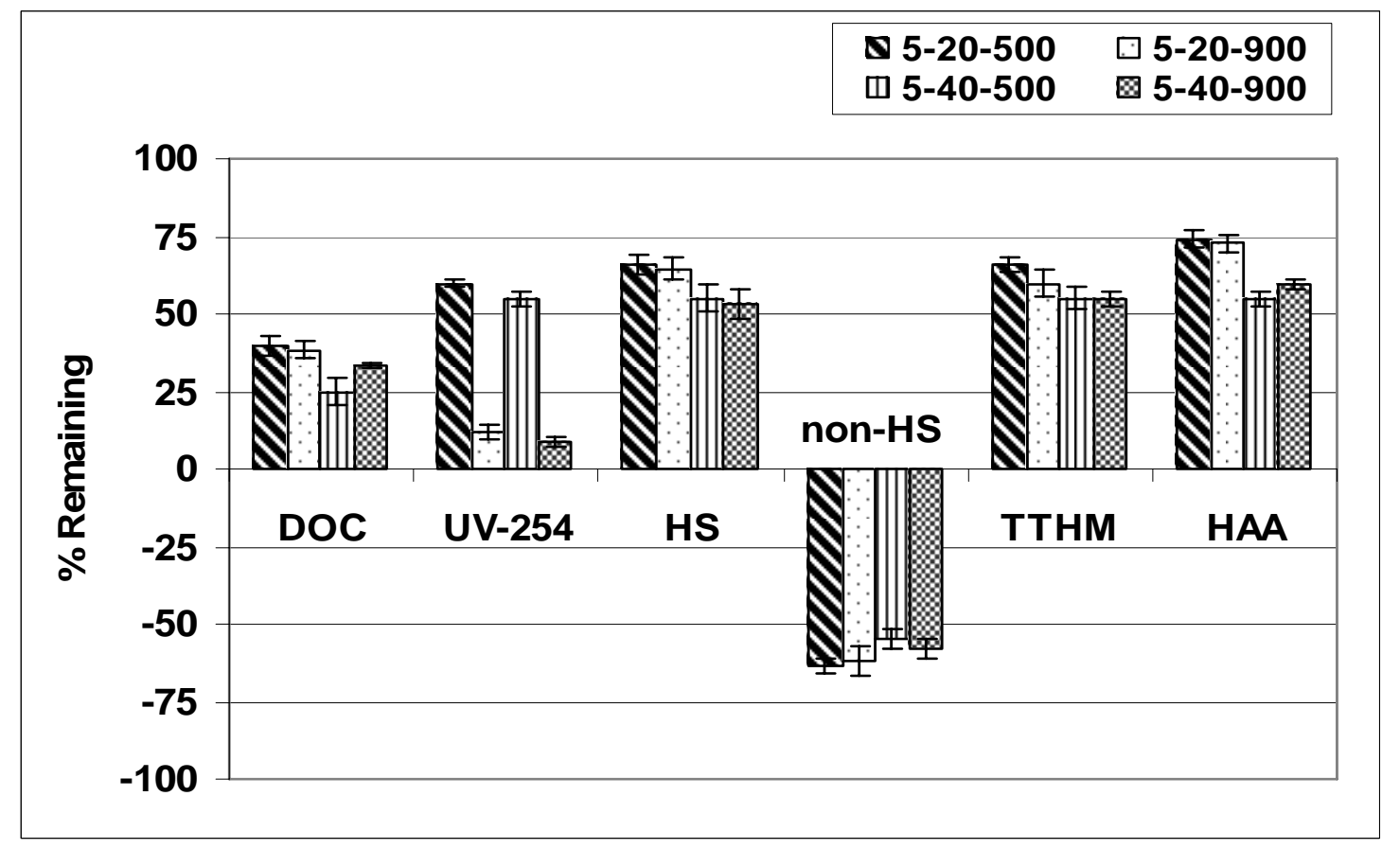

Fig.S8 Water quality for $P 1$ for two different sintering temperatures

Experimental setup: Fig. S1 Operating Conditions: Table 1. Membrane Size: 5 kD, 20 or 40 layers, oven-baked at $500^{\circ} \mathrm{C}$ or sintered at $900^{\circ} \mathrm{C}$. ${ }^{*}$ All values are average of triplicates within experiments. Explanation of the legend is described in the caption of Fig.1

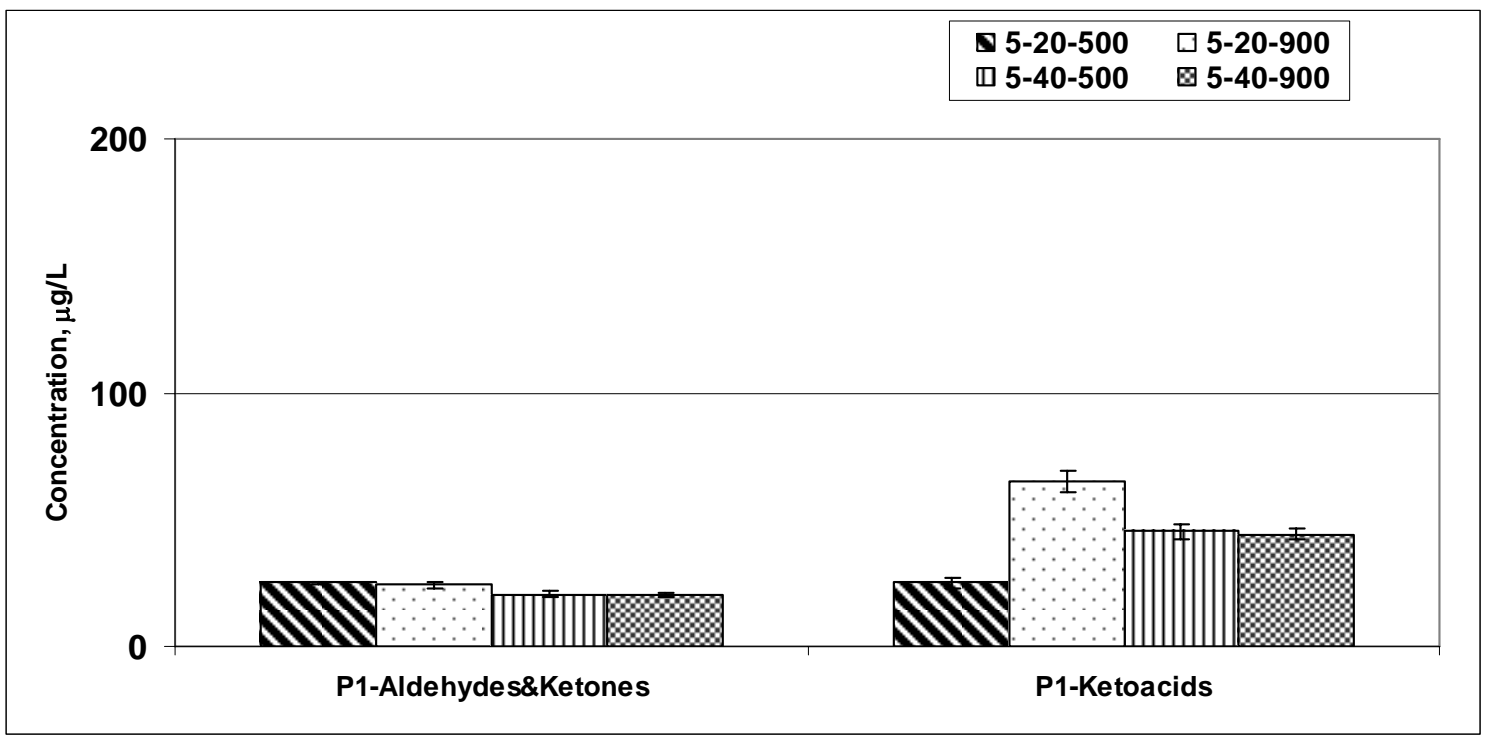

Fig.S9 Concentrations of ozonation by-products in P1 for two different sintering temperatures

Experimental setup: Fig. S1 Operating Conditions: Table 1. Membrane Size: 5 kD, 20 or 40 layers, oven-baked at $500^{\circ} \mathrm{C}$ or sintered at $900^{\circ} \mathrm{C}$. All values are average of triplicates within experiments Explanation of the legend is described in the caption of Fig.1 


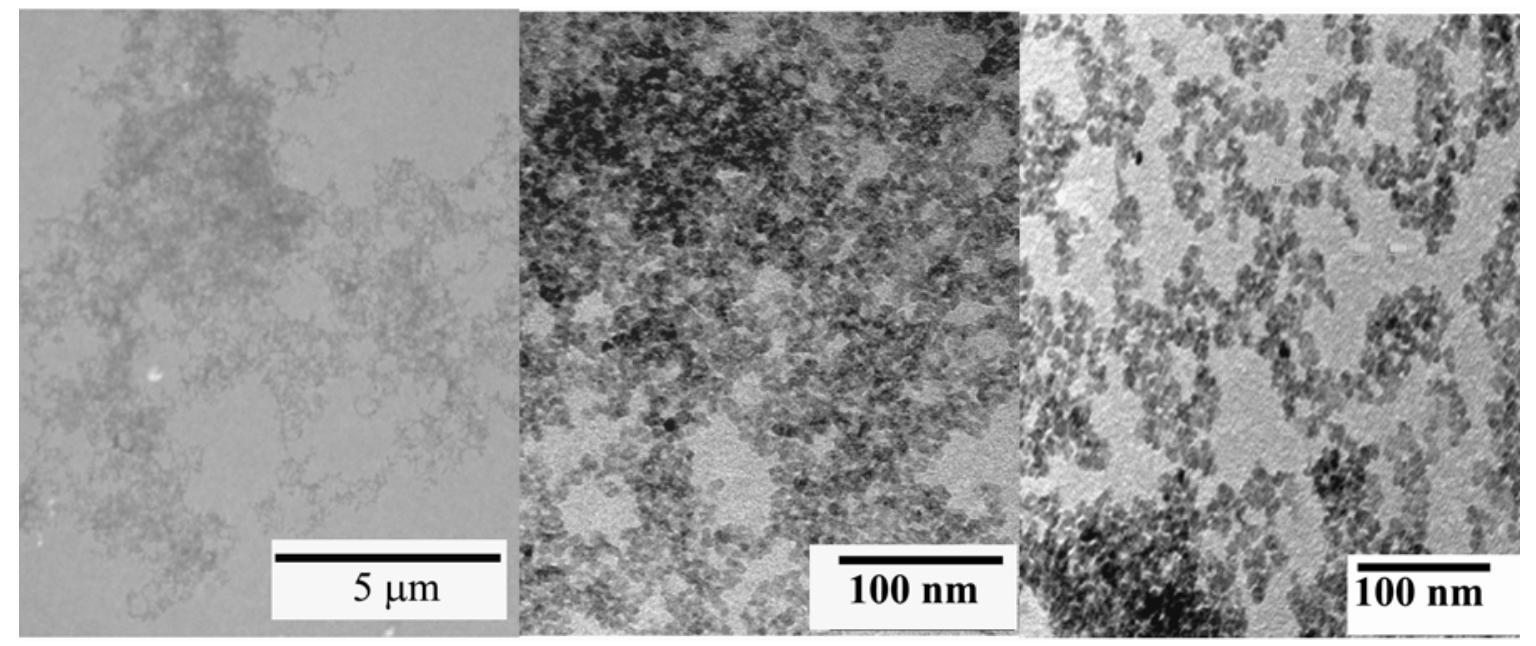

Fig.S10 TEM characterization of the iron oxide particles (average size 4-6nm) TEM: JEOL 100CX, Accelerating voltage: 100 kV, Imaging system: Analysis, Digital imaging: Mega view III

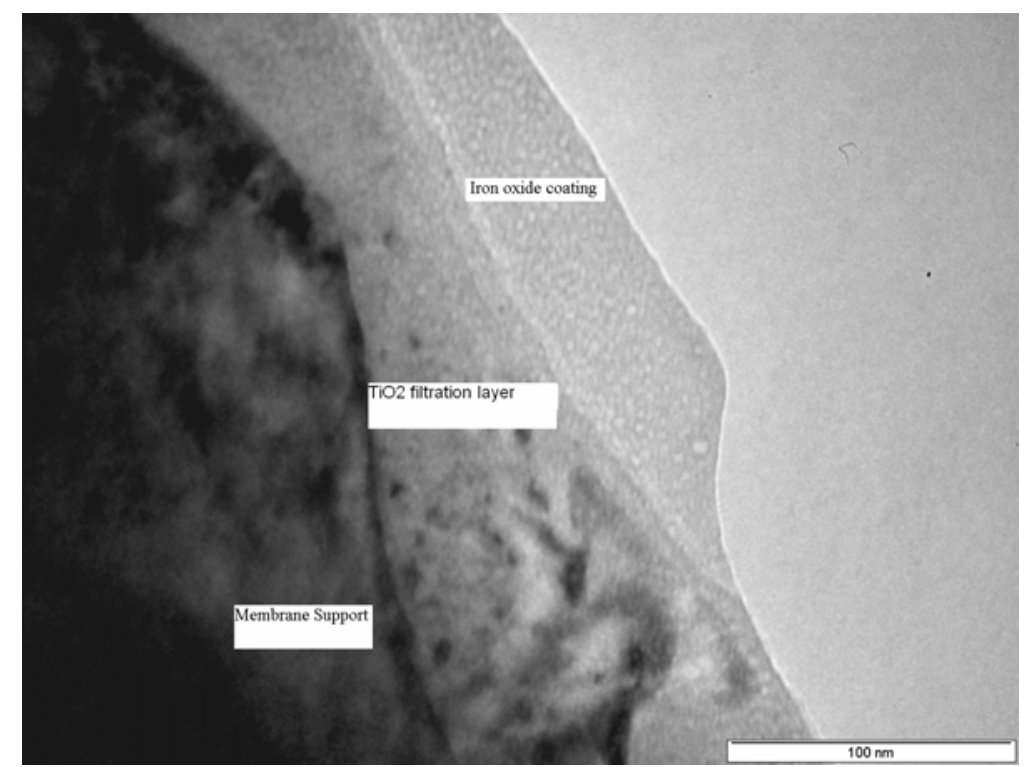

Fig.S11 Ceramic membrane coated with 40-layers of iron oxide particles Membrane Size: $5 \mathrm{kD}$, 40 layers iron oxide coating, sintered at $900^{\circ} \mathrm{C}$. TEM: JEOL 100CX, Accelerating voltage: $100 \mathrm{kV}$, Imaging system: Analysis, Digital imaging: Mega view III Ceramic membrane: $15 \mathrm{kD}$ MWCO, Iron oxide nanoparticles size: (4-6 nm), Sintering Temperature: $900{ }^{\circ} \mathrm{C}$ Average Fe2O3 coating thickness $\sim 50 \mathrm{~nm}$ 


\section{Table S1 Typical Characteristics of Lake Lansing Water (Haslett, MI)}

\begin{tabular}{|c|c|}
\hline Parameters & Lake Lansing \\
\hline TOC (mg/L) & 8.6 to 11.6 \\
\hline $\mathrm{pH}$ & 7.7 to 8.6 \\
\hline Alkalinity $\left(\mathrm{mg} / \mathrm{L}\right.$ as $\left.\mathrm{CaCO}_{3}\right)$ & 145 to 157 \\
\hline UV-254 (abs.) & 0.160 to 0.180 \\
\hline SDS THM $^{b}(\mu \mathrm{g} / \mathrm{L})$ & 240 \\
\hline SDS HAA $^{b}(\mu \mathrm{g} / \mathrm{L})$ & 75 \\
\hline $\mathrm{BDOC}(\mathrm{mg} / \mathrm{L})$ & 1.0 to 4.1 \\
\hline Nitrate (mg/L) & 0.44 \\
\hline Total Phosphate (mg/L) & 0.06 \\
\hline Hardness $\left(\mathrm{mg} / \mathrm{L}\right.$ as $\left.\mathrm{CaCO}_{3}\right)$ & 190 to 198 \\
\hline
\end{tabular}

${ }^{a}$ All data reported is obtained from the Lake Lansing Watershed Advisory Committee Report (1998) [37] except for the SDS THM and SDS HAA data, which were measured as part of this study

SDS THM and SDS HAA were measured using Standard Method 5710 and USEPA Method 552.2, respectively. 